\title{
Evaluation of the Effects of Processing Technique on Chemical Components in Raphani Semen by HPLC and UPLC-Q-TOF-MS
}

\author{
Sijia Gao $\mathbb{D}^{1},{ }^{1}$ Jirui Wang, ${ }^{1}$ Lei Cheng, ${ }^{1}$ Yuxin Fan, ${ }^{2}$ Weihan Qin, ${ }^{1}$ Yunhong Wang, \\ Yanlei Guo $\mathbb{D}$, ${ }^{1}$ Xiaomei Zhang $\mathbb{D},{ }^{1}$ and Yong Yang $\mathbb{D}^{1}$ \\ ${ }^{1}$ Chongqing Academy of Chinese Materia Medica, Chongqing, China \\ ${ }^{2}$ College of Pharmacy, Chengdu University of Traditional Chinese Medicine, Chengdu, Sichuan, China
}

Correspondence should be addressed to Xiaomei Zhang; 605050963@qq.com and Yong Yang; yangychem@126.com

Received 10 August 2021; Revised 10 November 2021; Accepted 17 December 2021; Published 4 January 2022

Academic Editor: Danilo Corradini

Copyright (c) 2022 Sijia Gao et al. This is an open access article distributed under the Creative Commons Attribution License, which permits unrestricted use, distribution, and reproduction in any medium, provided the original work is properly cited.

In this study, the effects of different processing techniques on the chemical components of Raphani Semen (RS) were evaluated. An established high-performance liquid chromatography (HPLC) method was adopted for the simultaneous determination of glucoraphanin, sinapine thiocyanate, raphanin, and erucic acid in the fried products of Raphani Semen to evaluate the chemical changes during frying processing as well as optimize the best frying technology of Raphani Semen. Then, the chemical components in the fried Raphani Semen were identified by ultrahigh-performance liquid chromatography-quadrupole time-of-flight mass spectrometry (UPLC-Q-TOF-MS). A total of 54 compounds in processed Raphani Semen were identified by UPLC-Q-TOFMS. The results showed that the content of glucoraphanin and sinapine thiocyanate was the highest in the fried products at $130^{\circ} \mathrm{C}$ for $10 \mathrm{~min}$, and the effect of "Enzyme Killing and Glycosides Preserving" was the best. Therefore, this condition was chosen as the best frying technology of Raphani Semen. This study provided a more scientific basis for evaluation of the quality of Raphani Semen fried products and optimization of the frying technology of Raphani Semen.

\section{Introduction}

Processing, pronounced as Paozhi in Chinese, is recognized as an ancient Chinese pharmaceutic technique developed over thousands of years to increase efficiency and decrease toxicity of herbs in the guidance of traditional Chinese medicine (TCM) theory [1]. According to TCM theory, processing can alter energetic nature and therapeutic direction, as well as improve flavor of herbal medicines, thereby increasing the therapeutic effectiveness and applicability in clinics. Most Chinese herbal medicines need to be properly processed to become decoction pieces and obtain the specific drug efficiency [2]. Processing technique encompasses roasting, baking, and stir-frying with or without liquid/solid excipient, by which decoction pieces with different therapeutic potencies can be derived from the same herb [3]. For instance, Coptidis rhizome (CR) is a commonly used Chinese medicine in clinics for the treatment of various inflammatory disorders and related diseases with the functions of clearing heat, drying dampness, and detoxification [4-6]. There were four processed CR, namely, raw CR, wine CR (stir-frying with wine), ginger CR (stir-frying with ginger), Evodiae Fructus CR (stirbaking with Evodiae Fructus) in the Chinese Pharmacopoeia (2020 Edition). Different processing methods are developed to guide and concentrate therapeutic effects of CR. Wine CR is inclined to treat insomnia, sore mouth, and red and swelling eyes [7-9], and ginger CR is prescribed for enhancing the effect preventing vomiting and expelling phlegm [10], while Evodiae Fructus CR is mainly used for curing diarrhea [7]. In a nutshell, processing is essential for safety and effectiveness of TCM as it may cause complicated changes in active chemical components, such as the contents may alter, the structures may change, and new compound occurred, and therefore, the functions of herbal medicines. But the underlying mechanisms of processing remain unclear for most TCM; therefore, investigation of the chemical changes of TCM before and after processing is key for understanding of underlying mechanisms. 
Raphani Semen (RS), the dried and mature seed of Raphanus sativus L., was first recorded in the Chinese herbal medicine "RiHuaZi Materia Medica" in the Five Dynasties [11]. It is pungent and sweet in flavor and has the effect of eliminating food and distension, qi-descending, and phlegm-resolving [12]. Therefore, it has been used for stagnation of diet, abdominal distension, constipation, retention of diarrhea, phlegm, and asthma in clinics. The chemical components of RS mainly include glucosides, alkaloids, volatile oils, fatty acids, flavonoids, and polysaccharides [13]. Pharmacological studies showed that RS had the functions of relieving asthma, suppressing cough, removing phlegm, antioxidation, and enhancing gastrointestinal motility $[14,15]$. Processing has been a major feature of TCM, and RS is one of the typical examples. In the theory of TCM, processing would affect the efficacy of RS, the unprocessed RS is good at inducing sputum, and after the frying process, it is good at reducing qi, resolving phlegm and eliminating food [16]. At present, fried RS is more widely used in clinics, and research studies have evaluated the contents change of glucoraphanin and sinapine thiocyanate before and after the frying process. Previous studies in China showed that the frying of RS played a role of "Enzyme Killing and Glycosides Preserving," inhibiting the activity of mustard enzyme in RS and preventing the decomposition of glucoraphanin [17]. It was indicated that the sulfur compounds were one of the material bases of RS with the characteristics of the efficacy varied with processing, which can be used as a specific quality control index to effectively reflect the degree of frying RS at the same time.

However, there were no reports on the identification of the active components and the changes of the components under different frying conditions. Through investigation, referring to the actual production of pharmaceutical enterprises and the pretest of the experiment in the early stage of our research group, the chemical components of the fried products of RS were qualitatively identified under different firing conditions. By determining the content of glucoraphanin, raphanin, erucic acid, and sinapine thiocyanate in RS, taking the content of water-soluble glucoraphanin as the main measurement standard, combined with the content of other three components and the overall profiles as auxiliary indexes, the frying process of RS was discussed, hoping to provide reference for the frying process and clinical application of RS.

\section{Materials and Methods}

2.1. Medicinal Materials. The RS used in the current experiment was purchased in the year of 2020 from Chongqing Shangyao Huiyuan Pharmaceutical Co., Ltd. and identified as the dried and mature seed of Raphanus sativus L. by Prof. Xianyou Qu, researcher of Institute of Pharmacognosy, Chongqing Academy of Chinese Materia Medica.

2.2. Chemicals, Reagents, and Instrumentation. The reference compounds sinapine thiocyanate (purity $\geq 98.0 \%$, batch number PS011003) and glucoraphanin (purity $\geq 95.0 \%$, batch number PS011849) were purchased from Chengdu Pusi Biotechnology Co., Ltd. The reference compounds raphanin (purity $\geq 98.0 \%$, batch number BP1814) and erucic acid (purity $\geq 98.0 \%$, batch number BP1778) were purchased from Chengdu Pulifa Technology Development Co., Ltd. Water used for all analyses was ultrapure water, the acetonitrile and methanol were chromatographic pure, and other reagents were analytical pure.

A Waters 2695 HPLC (Waters, Milford, MA, USA), Shimadzu LC-30A UPLC, and Triple TOF $^{\mathrm{TM}} 600$ Q-TOF-MS (Allen-Bradley company, USA, including Analyst 1.6 workstation, PeakView 1.2.0.3 data processing software) were adopted to conduct the content determination and quantitative analysis of RS. Shimadzu AEG-45SM fivedecimal electronic balance (Shimadzu, Kyoto, Japan) and BP121S One Over Ten Thousand Analytical Balance (Sartorius company, Germany) were used to weight. CY-25 Chinese medicine frying machine (Wenzhou Dingli Medical Instrument Co., Ltd.) was used to process RS.

2.3. Preparation of Fried Products of RS. Referring to the processing technology of RS from two pharmaceutical companies in Chongqing and the preliminary experiment of our research group, the processing conditions were set as given in Table 1 . About $500 \mathrm{~g}$ of RS was put in the frying machine, and the processing temperature and time for frying were set as given in Table 1.

2.4. Standard Preparation and Calibration Curve. The reference compounds glucoraphanin, sinapine thiocyanate, raphanin, and erucic acid were accurately weighed and dissolved in $1 \mathrm{~mL} \mathrm{50 \%} \mathrm{methanol} \mathrm{to} \mathrm{produce} \mathrm{a} \mathrm{mixed} \mathrm{standard} \mathrm{stock}$ solution with the concentrations of $0.256 \mathrm{mg} / \mathrm{mL}$, $0.0521 \mathrm{mg} / \mathrm{mL}, 0.193 \mathrm{mg} / \mathrm{mL}$, and $0.0357 \mathrm{mg} / \mathrm{mL}$, respectively. And $0.5,1,2,5,10,20$, and $30 \mu \mathrm{L}$ of the standard mixture were separately taken and diluted in $50 \%$ methanol for HPLC analysis to make calibration curves.

2.5. Sample Preparation. Half gram of fried RS powder was extracted by ultrasonic (power $250 \mathrm{~W}$, frequency $40 \mathrm{~Hz}$, temperature $30^{\circ} \mathrm{C}$ ) with $50 \mathrm{~mL}$ water for $30 \mathrm{~min}$ and filtered.

2.6. Chromatographic Conditions. HPLC condition: chromatographic column: Agilent SB-C ${ }_{18}(4.6 \times 250 \mathrm{~mm}, 5 \mu \mathrm{m})$; mobile phase: acetonitrile (A) $-0.1 \%$ phosphoric acid solution (B), gradient elution $(0 \sim 15 \mathrm{~min}, 5 \% \mathrm{~A} \longrightarrow 8 \% \mathrm{~A}$; $15-25 \mathrm{~min}, 8 \% \mathrm{~A} \longrightarrow 20 \% \mathrm{~A} ; 25-40 \mathrm{~min}, 20 \% \mathrm{~A} \longrightarrow 24 \% \mathrm{~A}$; $40-50 \mathrm{~min}, 24 \% \mathrm{~A} \longrightarrow 45 \% \mathrm{~A} ; 50-52 \mathrm{~min}, 45 \% \mathrm{~A} \longrightarrow 5 \% \mathrm{~A}$; 52-55 min, $5 \% \mathrm{~A} \longrightarrow 5 \% \mathrm{~A}$ ); detection wavelength: $225 \mathrm{~nm}$; column temperature: $30^{\circ} \mathrm{C}$; current velocity: $1 \mathrm{~mL} \cdot \mathrm{min}^{-1}$; sample size: $10 \mu \mathrm{L}$. The compounds were quantified by dividing the peak areas of the compounds of interest by the peak area of the standard compound [18].

UPLC-Q-TOF-MS condition: the chromatographic column adopted in current study was ACE Excel Super $\mathrm{C}_{18}$ chromatographic column $(2.1 \times 100 \mathrm{~mm}, 3 \mu \mathrm{m})$, and column temperature was $30^{\circ} \mathrm{C}$. The mobile phase was acetonitrile 
TABLE 1: Sample information of RS in different processing temperature and time.

\begin{tabular}{lcc}
\hline No. & $T\left({ }^{\circ} \mathrm{C}\right)$ & $t(\min )$ \\
\hline L1 & 70 & 10 \\
L2 & 70 & 20 \\
L3 & 70 & 30 \\
L4 & 70 & 40 \\
L5 & 90 & 10 \\
L6 & 90 & 20 \\
L7 & 90 & 30 \\
L8 & 90 & 40 \\
L9 & 110 & 10 \\
L10 & 110 & 20 \\
L11 & 110 & 30 \\
L12 & 110 & 40 \\
L13 & 130 & 10 \\
L14 & 130 & 20 \\
L15 & 130 & 30 \\
L16 & 130 & 40 \\
\hline
\end{tabular}

(A) $-0.1 \%$ formic acid aqueous solution (B) with gradient elution $(0-1 \mathrm{~min}, 15 \% \mathrm{~A}$; $1-8.5 \mathrm{~min}, 15 \% \mathrm{~A} \longrightarrow 85 \% \mathrm{~A}$, $8.5-11.5 \mathrm{~min}, \quad 85 \% \mathrm{~A} ; \quad 11.5-11.6 \mathrm{~min}, \quad 85 \% \mathrm{~A} \longrightarrow 15 \% \mathrm{~A}$; $11.6-15 \mathrm{~min}, 15 \% \mathrm{~A})$. The flow rate was set at $0.25 \mathrm{~mL} / \mathrm{min}$, and the injection volume was $3 \mu \mathrm{L}$.

Mass spectrometry condition: ESI-positive IDA mode was used to collect data. ISVF: +5.5 kV; GS1: $0.40 \mathrm{MPa}$; CUR: $0.14 \mathrm{MPa}$; GS2: $0.35 \mathrm{MPa}$; TEMP: $600^{\circ} \mathrm{C}$; DP: $60 \mathrm{~V}$; CE: $50 \mathrm{~V}$; CES: $\pm 15 \mathrm{~V}$. The detection mode was IDA, MMDF and DBS were the conditions to trigger the second level scanning, and the second level scanning was preferred when the conditions were met.

2.7. Data Analysis. Referring to the related literature on the chemical constituents of RS, a high-resolution mass spectrometry screening database for chemical components of RS was constructed. PeakView software was used to extract and analyze the 16 batch samples data of different processing conditions collected by Q-TOF, and the target compounds were the ions with mass error less than $5 \mathrm{ppm}$, correct isotope distribution, and secondary fragments. Combined with the functions of formula finder, mass calculators, online databases (ChemSpider, METLIN, and HMDB) and secondary fragmentation rules, the chemical structures of the known components of RS were identified and verified.

\section{Results}

3.1. Method Development and Validation. Detailed experimental results can be found in the previous study published by our research group [19]. As shown in Figure 1, the HPLC method ensured sufficient chromatographic separation and accurate and precise quantification of glucoraphanin, sinapine thiocyanate, raphanin, and erucic acid. The linear regression equations obtained for four analytes are given in Table 2, and the sample concentrations in this experiment were within the established linear range. The HPLC method was validated for its linearity, precision, stability, repeatability, and recovery. The results of instrumental precision showed that the RSDs\% of peak areas for four analytes (glucoraphanin, sinapine thiocyanate, raphanin, and erucic acid) were less than $1 \%(0.97 \%$, $0.78 \%, 0.81 \%$, and $0.97 \%$, respectively), indicating that the analysis instrument was in good precision condition. The RSDs $\%$ (in the reference compounds) results of glucoraphanin, sinapine thiocyanate, raphanin, and erucic acid were $0.86 \%$, $0.89 \%, 0.46 \%$, and $0.79 \%$, respectively; The RSDs\% (in the samples) results of glucoraphanin, sinapine thiocyanate, raphanin, and erucic acid were $1.04 \%, 0.78 \%, 0.91 \%$, and $1.27 \%$, respectively, which indicated that the stability of reference solution and sample solution was good within $48 \mathrm{~h}$. All samples in this experiment were tested within $48 \mathrm{~h}$ from sample preparation. The repeatability assessment in the established method shown that RSDs\% of glucoraphanin, sinapine thiocyanate, raphanin, and erucic acid were $1.01 \%, 1.26 \%, 1.08 \%$, and $1.32 \%$, respectively, which indicated that the method was with good repeatability. The established method also had acceptable accuracy with spike recovery, which were $100.14 \%$, $99.61 \%, 99.05 \%$, and $99.52 \%$, respectively, with RSDs\% of $1.94 \%, 2.34 \%, 1.86 \%$, and $2.17 \%$ for glucoraphanin, sinapine thiocyanate, raphanin, and erucic acid, respectively. The method was successfully employed for quantitative determination of glucoraphanin, sinapine thiocyanate, raphanin, and erucic acid in raw and fried RS samples.

3.2. Effects of Processing Technique on RS. As given in Table 3 , the glucoraphanin was not detected in the water extract of RS after frying at $70-90^{\circ} \mathrm{C}$ for $10-40 \mathrm{~min}$. With the increase of frying time to $110^{\circ} \mathrm{C}$, the content of glucoraphanin increased gradually. At temperature of $130^{\circ} \mathrm{C}$, the content of glucoraphanin decreased gradually to undetectable with the increased frying time in the range of $10-40 \mathrm{~min}$. Samples frying at $130^{\circ} \mathrm{C}$ for $10 \mathrm{~min}$ obtained the highest content of glucoraphanin. The results indicated that the content of glucoraphanin is closely related to the processing time and temperature. At a lower processing temperature, glucoraphanin will be hydrolyzed by myrosinase during the extraction process with water as the medium. When the processing temperature is too high, glucoraphanin may be directly destroyed. For sinapine thiocyanate, when the temperature is from $70^{\circ} \mathrm{C}$ to $110^{\circ} \mathrm{C}$, with the increased frying temperature and time, the content of it in water extract also increased. The content of sinapine thiocyanate was the highest when frying at $130^{\circ} \mathrm{C}$ for $10 \mathrm{~min}$, and with the increase of frying time, the content of which decreased rapidly. When it comes to raphanin, at the frying temperature of $70-90^{\circ} \mathrm{C}$, the content of raphanin increased gradually. Reaching the temperature of $110^{\circ} \mathrm{C}$, with the increased frying time, the content of raphanin decreased rapidly to undetectable. The results showed that raphanin and glucoraphanin hardly coexist in the same water-extracted sample. By literature review, it was found that the glucoraphanin was hydrolyzed to raphanin by myrosinase, which exactly explained the phenomenon of the current experiment $[20,21]$. The content of erucic acid was not affected significantly by frying time at the temperature of $70^{\circ} \mathrm{C}$. But when the frying temperature reached $90^{\circ} \mathrm{C}$, content of erucic acid began to decrease to undetectable with the increase of temperature and time. 


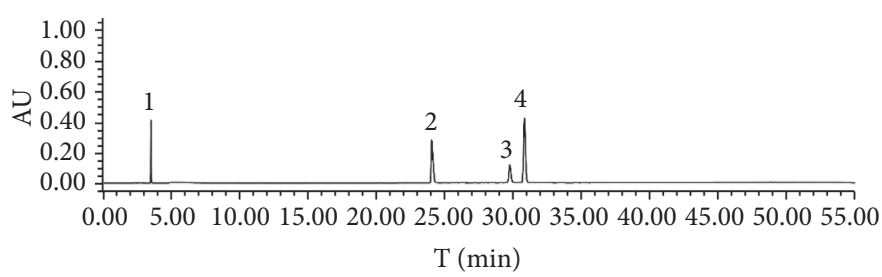

(a)

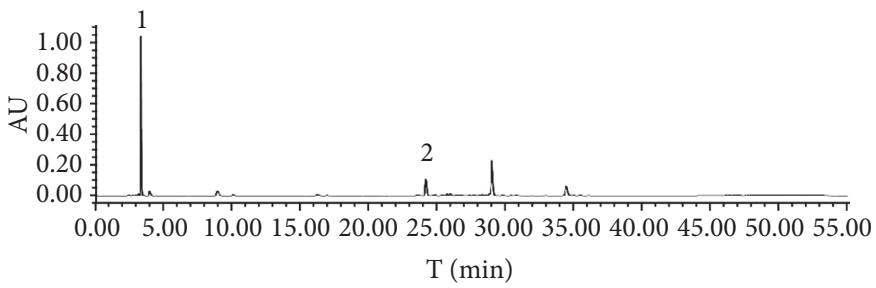

(b)

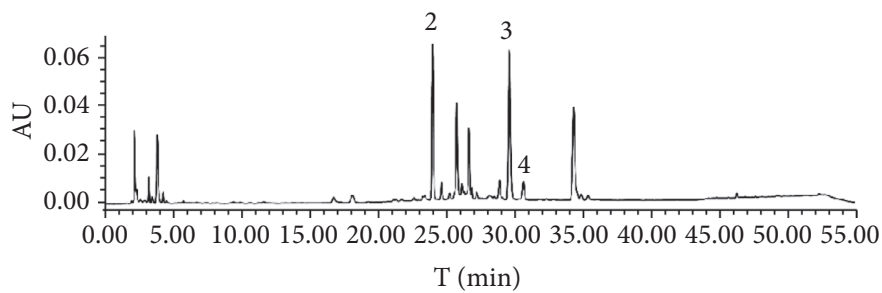

(c)

Figure 1: HPLC chromatograms of mixed reference substances. (a) Raphanus semen in $240^{\circ} \mathrm{C}$ for $10 \mathrm{~min}$ (b) and $120^{\circ} \mathrm{C}$ for 20 min (c). 1 , glucoraphanin; 2 , sinapine thiocyanate; 3 , raphanin; 4 , erucic acid.

TABLE 2: Regression equation and linear range.

\begin{tabular}{lccc}
\hline Compound & Regression equation & Linear range $(\mu \mathrm{g})$ & $r$ \\
\hline Glucoraphanin & $Y=992029.90-5949.49 X$ & $0.1280-7.680$ & 0.9999 \\
Sinapine thiocyanate & $Y=2694619.00-578.74 X$ & $0.0261-1.563$ & 0.9999 \\
Raphanin & $Y=645660.40+2759.24 X$ & $0.0965-5.790$ & 0.9999 \\
Erucic acid & $Y=3668510.67+3213.65 X$ & $0.0179-1.071$ & 0.9999 \\
\hline
\end{tabular}

3.3. Comparison of the Overall Profile. In order to comprehensively compare the changes of components in RS during the frying process, the overall profiles of chemical components in RS at different frying temperature and time were overlapped [22]. The results are shown in Figure 2. From the overall profiles of different fried products, 32 main chromatographic peaks were detected in 16 samples. With the increased frying temperature and frying time, the number and height of chromatographic peaks before $10 \mathrm{~min}$ were increased, indicating that high frying temperature could preserve the large polar components including glucoraphanin (peak 2). The peaks in $24-30 \mathrm{~min}$ were also affected by the frying process. The peak area of No. 15 peak (sinapine thiocyanate) changed more smoothly and showed an overall upward trend, but long-time frying at high temperature could also destroy the component, which was consistent with the determination of chemical composition. The peak areas of No. 18, No. 19, No. 22 (raphanin), and No. 23 (erucic acid) decreased with the increase of frying temperature and time, while the peak areas of No. 21 showed an increasing trend. The peak area of No. 24 also decreased sharply when fried for a long time at high temperature (L15 and L16), while the peak area of No. 27, No. 28, No. 29, No. 31 , and No. 32 gradually increased under high temperature (L14, L15, and L16).

3.4. Identification of the Chemical Composition of Processed $R S$. In this study, the UPLC-Q-TOF-MS method was further introduced to analyze and identify chemical components of RS in combination with online database. The total ion chromatogram of processed RS is shown in Figure 3. The molecular formula information of the compound was obtained by PeakView1.2 to fit the element composition from the first-order MS. The structures of each compound were inferred by analyzing the fragmentation law of MS combined with the network databases such as HMDB and MassBank. A total of 54 chemical components in fried RS were identified in this study, including thioglycoside, alkaloids, volatile oils, fatty acids, and other components, as given in Table 4. 
TABLE 3: The mean contents of the 4 components in RS samples by different processing technologies $(n=2)$.

\begin{tabular}{|c|c|c|c|c|}
\hline No. & Glucoraphanin (\%) & Sinapine thiocyanate (\%) & Raphanin (\%) & Erucic acid (\%) \\
\hline L1 & - & 0.25 & 1.09 & 0.02 \\
\hline $\mathrm{L} 2$ & - & 0.24 & 1.01 & 0.02 \\
\hline L3 & - & 0.33 & 1.34 & 0.03 \\
\hline $\mathrm{L} 4$ & - & 0.28 & 1.16 & 0.02 \\
\hline L5 & - & 0.32 & 1.30 & 0.02 \\
\hline L6 & - & 0.35 & 1.41 & 0.01 \\
\hline L7 & - & 0.33 & 1.40 & 0.01 \\
\hline L8 & - & 0.38 & 1.56 & 0.01 \\
\hline L9 & - & 0.38 & 1.35 & 0.01 \\
\hline L10 & 1.61 & 0.38 & 0.35 & - \\
\hline L11 & 2.84 & 0.39 & - & - \\
\hline L12 & 3.44 & 0.35 & - & - \\
\hline L13 & 3.92 & 0.41 & - & - \\
\hline L14 & 2.09 & 0.39 & - & - \\
\hline L15 & 0.07 & 0.30 & - & - \\
\hline L16 & - & 0.21 & - & - \\
\hline
\end{tabular}

Note. "-" means that it is not detected at the current concentration.

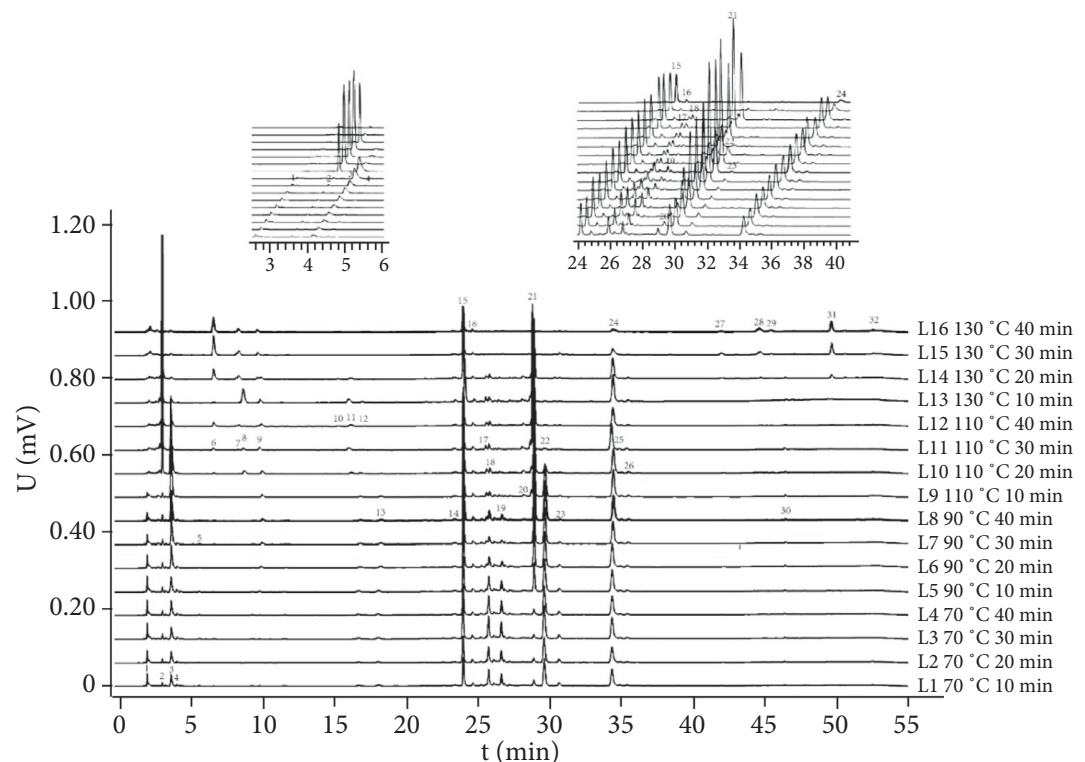

FIGURE 2: Overall chromatograms of 16 batches of RS-processed products.

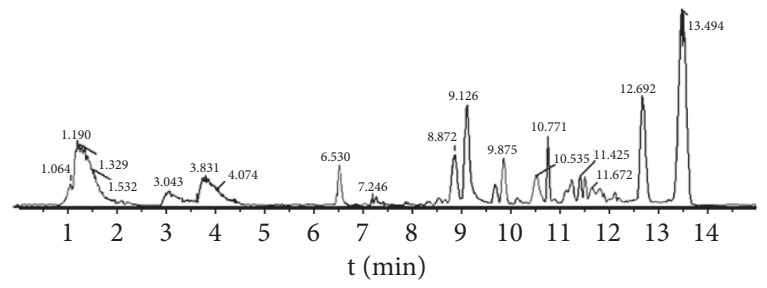

FIgURE 3: Total ion chromatogram of processed RS (Raphanus semen frying in $240^{\circ} \mathrm{C}$ for $\left.10 \mathrm{~min}\right)$.

\section{Discussion}

In general, enzyme (myrosinase) hydrolysis occurs in chemical components of raw RS during rinsing or warm water treatment, and to prevent the active ingredients from enzyme hydrolysis, the processing technique was introduced to medicinal herbs in TCM clinics. Usually, through heating and frying, the activity of myrosinase can be inhibited [23], so as to achieve the effect of "Enzyme Killing and Glycosides Preserving," which reflects the characteristics of the efficacy varied with processing [24]. The myrosinase in raw RS can play its enzymatic activity in water, transfer hydrolyze glucoraphanin to raphanin, and stir frying can make the myrosinase lose its activity, while using water heating extraction will not lead to the decomposition of glucoraphanin, so using water as the extraction solvent can reflect whether the frying degree is appropriate; thus, water was used as the extraction solvent in this study. In the current study, we found that different frying temperature and time had great influence on the chemical composition of RS. A small amount of glucoraphanin could be detected in samples frying at $110^{\circ} \mathrm{C}$ for $20 \mathrm{~min}$, which indicated that myrosinase was inhibited, but not completely inactivated. The content of 
TABLE 4: Identification of the chemical composition of processed RS.

\begin{tabular}{|c|c|c|c|c|c|}
\hline \multirow[b]{2}{*}{$\begin{array}{l}\text { Retention time } \\
(\mathrm{min})\end{array}$} & \multicolumn{2}{|c|}{ Mass $(m / z)$} & \multirow[b]{2}{*}{$\begin{array}{l}\text { Deviation } \\
(\mathrm{ppm})\end{array}$} & \multirow[b]{2}{*}{ Formula } & \multirow[b]{2}{*}{ Components name } \\
\hline & $\begin{array}{l}\text { Theoretical } \\
\text { value }\end{array}$ & $\begin{array}{l}\text { Measured } \\
\text { value }\end{array}$ & & & \\
\hline 7.01 & 94.9984 & 94.9981 & 3.1 & $\mathrm{C}_{2} \mathrm{H}_{6} \mathrm{~S}_{2}$ & Dimethyl disulfide \\
\hline 13.74 & 126.9704 & 126.9699 & 3.9 & $\mathrm{C}_{2} \mathrm{H}_{6} \mathrm{~S}_{3}$ & Dimethyl trithioether \\
\hline 14.67 & 127.0060 & 127.0063 & 2.3 & $\mathrm{C}_{2} \mathrm{H}_{6} \mathrm{O}_{4} \mathrm{~S}$ & Dimethyl sulfate \\
\hline 14.64 & 158.9425 & 158.9421 & 2.5 & $\mathrm{C}_{2} \mathrm{H}_{6} \mathrm{~S}_{4}$ & Dimethyl tetrasulfide \\
\hline 1.25 & 123.0297 & 123.0291 & 4.8 & $\mathrm{C}_{4} \mathrm{H}_{10} \mathrm{~S}_{2}$ & 1,1-Bis(methylthio)methane \\
\hline 3.91 & 113.0233 & 113.0232 & 0.8 & $\mathrm{C}_{5} \mathrm{H}_{4} \mathrm{O}_{3}$ & 5-Hydroxymethylfurfural \\
\hline 1.56 & 141.0182 & 141.0185 & 2.1 & $\mathrm{C}_{6} \mathrm{H}_{4} \mathrm{O}_{4}$ & Coumalic acid \\
\hline 1.62 & 127.0390 & 127.0390 & 0.1 & $\mathrm{C}_{6} \mathrm{H}_{6} \mathrm{O}_{3}$ & 5-Hydroxymethylfurfural \\
\hline 3.91 & 177.0394 & 177.0392 & 1.1 & $\mathrm{C}_{6} \mathrm{H}_{8} \mathrm{O}_{6}$ & Vitamin C \\
\hline 7.81 & 99.0804 & 99.0805 & 0.7 & $\mathrm{C}_{6} \mathrm{H}_{10} \mathrm{O}$ & $\alpha$ - $\beta$-Vinyl aldehyde \\
\hline 4.73 & 119.1067 & 119.1066 & 0.8 & $\mathrm{C}_{6} \mathrm{H}_{14} \mathrm{O}_{2}$ & 1,1-Dimethoxy-2-methylpropane \\
\hline 1.56 & 144.0478 & 144.0481 & 2.0 & $\mathrm{C}_{6} \mathrm{H}_{9} \mathrm{NOS}$ & (4E)-5-(Methylsulfinyl)pent-4-enenitrile \\
\hline 3.90 & 178.0355 & 178.0358 & 1.6 & $\mathrm{C}_{6} \mathrm{H}_{11} \mathrm{NOS}_{2}$ & Glucoraphanin \\
\hline 3.91 & 176.0198 & 176.0204 & 3.3 & $\mathrm{C}_{6} \mathrm{H}_{9} \mathrm{NOS}_{2}$ & Raphanin \\
\hline 1.47 & 144.0842 & 144.0840 & 1.3 & $\mathrm{C}_{7} \mathrm{H}_{13} \mathrm{NS}$ & Hexyl isothiocyanate \\
\hline 1.14 & 191.0736 & 191.0732 & 2.1 & $\mathrm{C}_{8} \mathrm{H}_{14} \mathrm{O}_{3} \mathrm{~S}$ & (4E)-Ethyl 5-(methylsulfinyl)pent-4-enoate, 5 \\
\hline 13.49 & 113.1325 & 113.1324 & 0.9 & $\mathrm{C}_{8} \mathrm{H}_{16}$ & Cyclohexane,1,3-dimethyl \\
\hline 2.40 & 181.0495 & 181.0499 & 2.2 & $\mathrm{C}_{9} \mathrm{H}_{8} \mathrm{O}_{4}$ & Caffeic acid \\
\hline 1.18 & 165.0546 & 165.0547 & 0.7 & $\mathrm{C}_{9} \mathrm{H}_{8} \mathrm{O}_{3}$ & Phenylpyruvic acid \\
\hline 5.95 & 162.0550 & 162.0553 & 2.1 & $\mathrm{C}_{9} \mathrm{H}_{7} \mathrm{NO}_{2}$ & 4-Hydroxy-3-indolaldehyde \\
\hline 3.69 & 195.0652 & 195.0660 & 4.4 & $\mathrm{C}_{10} \mathrm{H}_{10} \mathrm{O}_{4}$ & Ferulic acid \\
\hline 1.83 & 209.0808 & 209.0805 & 1.4 & $\mathrm{C}_{11} \mathrm{H}_{12} \mathrm{O}_{4}$ & trans-Ferulic acid methyl \\
\hline 3.68 & 225.0758 & 225.0767 & 4 & $\mathrm{C}_{11} \mathrm{H}_{12} \mathrm{O}_{5}$ & Sinapic acid \\
\hline 10.20 & 223.0965 & 223.0971 & 2.6 & $\mathrm{C}_{12} \mathrm{H}_{14} \mathrm{O}_{4}$ & Ethyl ferulate \\
\hline 4.04 & 239.0914 & 239.0907 & 2.9 & $\mathrm{C}_{12} \mathrm{H}_{14} \mathrm{O}_{5}$ & Antithiamine factor \\
\hline 1.45 & 438.0557 & 438.0570 & 2.9 & $\mathrm{C}_{12} \mathrm{H}_{23} \mathrm{NO}_{10} \mathrm{~S}_{3}$ & Raphthioglucoside \\
\hline 1.21 & 278.1196 & 278.1197 & 0.4 & $\mathrm{C}_{12} \mathrm{H}_{17} \mathrm{CN}_{4} \mathrm{OS}$ & Vitamin B1 \\
\hline 13.49 & 279.1591 & 279.1592 & 0.5 & $\mathrm{C}_{16} \mathrm{H}_{22} \mathrm{O}_{4}$ & Dibutyl phthalate \\
\hline 14.18 & 257.2475 & 257.2487 & 4.6 & $\mathrm{C}_{16} \mathrm{H}_{32} \mathrm{O}_{2}$ & Palmitic acid \\
\hline 6.86 & 247.1931 & 247.1933 & 0.8 & $\mathrm{C}_{16} \mathrm{H}_{24} \mathrm{NO}$ & Sinapine \\
\hline 1.84 & 333.0969 & 333.0967 & 0.6 & $\mathrm{C}_{17} \mathrm{H}_{16} \mathrm{O}_{7}$ & Erucic acid-5-hydroxymethyl furfural ester \\
\hline 1.63 & 377.1456 & 377.1466 & 2.6 & $\mathrm{C}_{17} \mathrm{H}_{20} \mathrm{~N}_{4} \mathrm{O}_{6}$ & Vitamin B2 \\
\hline 3.20 & 369.1479 & 369.1489 & 2.7 & $\mathrm{C}_{17} \mathrm{H}_{24} \mathrm{~N}_{2} \mathrm{O}_{5} \mathrm{~S}$ & trans-sinapine thiocyanate \\
\hline 10.41 & 281.2475 & 281.2486 & 3.7 & $\mathrm{C}_{18} \mathrm{H}_{32} \mathrm{O}_{2}$ & Linoleic acid \\
\hline 9.79 & 285.2788 & 285.2781 & 2.4 & $\mathrm{C}_{18} \mathrm{H}_{36} \mathrm{O}_{2}$ & Stearic acid \\
\hline 8.44 & 279.2319 & 279.2328 & 3.5 & $\mathrm{C}_{18} \mathrm{H}_{30} \mathrm{O}_{2}$ & Linolenic acid \\
\hline 12.26 & 283.2632 & 283.2638 & 2.1 & $\mathrm{C}_{18} \mathrm{H}_{34} \mathrm{O}_{2}$ & Oleic acid \\
\hline 10.92 & 311.2945 & 311.2943 & 0.6 & $\mathrm{C}_{20} \mathrm{H}_{38} \mathrm{O}_{2}$ & Eicosenoic acid \\
\hline 1.18 & 313.3101 & 313.3108 & 2.2 & $\mathrm{C}_{20} \mathrm{H}_{40} \mathrm{O}_{2}$ & Arachidic acid \\
\hline 1.48 & 452.1374 & 452.1358 & 3.5 & $\mathrm{C}_{21} \mathrm{H}_{25} \mathrm{NO}_{8} \mathrm{~S}$ & $\begin{array}{c}\text { (4E)-5-[(6-O-Feruloyl)- } \beta \text {-D-glucopyranosylsulfanyl }] \\
\text { pent- } 4 \text {-enenitrile }\end{array}$ \\
\hline 12.03 & 339.3258 & 338.3255 & 0.9 & $\mathrm{C}_{22} \mathrm{H}_{42} \mathrm{O}_{2}$ & Erucic acid \\
\hline 12.03 & 338.3417 & 338.3423 & 1.6 & $\mathrm{C}_{22} \mathrm{H}_{43} \mathrm{NO}$ & Dodecanoic acid (cis-13) \\
\hline 1.68 & 479.1184 & 479.1207 & 4.7 & $\mathrm{C}_{22} \mathrm{H}_{22} \mathrm{O}_{12}$ & Isorhamnetin-3-O-glucoside \\
\hline 1.09 & 482.1479 & 482.1470 & 1.8 & $\mathrm{C}_{22} \mathrm{H}_{27} \mathrm{NO}_{9} \mathrm{~S}$ & $\begin{array}{c}\text { (4E)-5-(6-O-Sinapoly)- } \beta \text {-D-glucopyranosylsulfanyl }] \\
\text { pent-4-enenitrile }\end{array}$ \\
\hline 9.98 & 367.3571 & 367.3579 & 2.2 & $\mathrm{C}_{24} \mathrm{H}_{46} \mathrm{O}_{2}$ & Ethyl erucate \\
\hline 2.11 & 579.1708 & 579.1721 & 2.2 & $\mathrm{C}_{27} \mathrm{H}_{30} \mathrm{O}_{14}$ & Kaempferol 3,7-O- $\alpha$-L-rhamnoside \\
\hline 9.52 & 399.3621 & 399.3611 & 2.5 & $\mathrm{C}_{28} \mathrm{H}_{46} \mathrm{O}$ & (22E,24R)-Ergostere-5, 22-diene- $3 \beta$-alcohol \\
\hline 1.71 & 641.1712 & 641.1716 & 0.6 & $\mathrm{C}_{28} \mathrm{H}_{32} \mathrm{O}_{17}$ & Isorhamnetin $3,4^{\prime}$-o- $\beta$-d-disglucoside \\
\hline 8.28 & 415.3934 & 415.3933 & 0.2 & $\mathrm{C}_{29} \mathrm{H}_{50} \mathrm{O}$ & $\beta$-Sitosterol \\
\hline 9.30 & 412.3700 & 412.3694 & 1.4 & $\mathrm{C}_{29} \mathrm{H}_{47} \mathrm{O}$ & Stigmast-4-en-3-one \\
\hline 9.44 & 423.4924 & 423.4913 & 2.6 & $\mathrm{C}_{30} \mathrm{H}_{62}$ & Triacontane \\
\hline 3.21 & 755.2393 & 755.2413 & 2.7 & $\mathrm{C}_{34} \mathrm{H}_{42} \mathrm{O}_{19}$ & $\begin{array}{l}\beta \text {-D-(3-Sinapoyl)frucofuranosyl- } \alpha \text {-D-(6-sinapoyl) } \\
\text { glucopyranoside }\end{array}$ \\
\hline 11.20 & 577.4463 & 577.4450 & 2.2 & $\mathrm{C}_{35} \mathrm{H}_{60} \mathrm{O}_{6}$ & $\beta$-Stigmaster-3-O- $\beta$-D-glucoside \\
\hline 11.09 & 961.2972 & 961.2930 & 4.4 & $\mathrm{C}_{45} \mathrm{H}_{52} \mathrm{O}_{23}$ & $\begin{array}{l}\beta-\mathrm{D} \text {-(3,4-Disinapoyl)frucofuranosyl- } \alpha \text {-D-(6- } \\
\text { sinapoyl) glucopyranosidec }\end{array}$ \\
\hline
\end{tabular}


glucoraphanin reached the maximum at $130^{\circ} \mathrm{C}$ for $10 \mathrm{~min}$, which indicated that this condition had the strongest inhibitory effect on myrosinase. However, with the increase of frying time, the content of glucoraphanin began to decline or even could not be detected. At the same time, the samples also began to change from the fried state to the scorched state, indicating that if the frying time was too long, glucoraphanin would be destroyed and decomposed by high temperature. When fried at $130^{\circ} \mathrm{C}$ for $10 \mathrm{~min}$, the contents of glucoraphanin and sinapine thiocyanate in the fried products were the highest, and the chromatographic peaks of many unknown components in the overall profile were also higher. Under this condition, the fried products of RS were bulging, and the seed coat was easy to twist off, with rich in oil and special aroma and high identification of external properties. Therefore, according to the changes of chemical composition and the characteristics, the frying process of RS at $130^{\circ} \mathrm{C}$ for $10 \mathrm{~min}$ was selected as the best processing condition. This study provided the basis for scientific evaluation of the quality control of RS and standardization of the frying process.

\section{Conclusion}

Our study revealed that in the process of frying RS, on the one hand, it should be prevented that the frying temperature and time were not enough to achieve the purpose of "Enzyme Killing and Glycosides Preserving," and on the other hand, it should also pay attention to the improper frying temperature and time, which will cause scorch and destroy the effective ingredients. A total of 54 chemical components in fried RS were identified in this study, including thioglycoside, alkaloids, volatile oils, fatty acids and other components. This study only discussed the frying process of RS from the chemical composition changes, and the next step is to verify the frying process combined with pharmacodynamic research, so as to provide a more comprehensive reference for the frying process and clinical application of RS.

\section{Data Availability}

The data used to support the findings of this study are available from the corresponding author upon request.

\section{Conflicts of Interest}

The authors declare that they have no conflicts of interest.

\section{Acknowledgments}

This work was supported by grants from the Natural Science Foundation of Chongqing (cstc2018jcyjAX0142) and Basic Scientific Research Funds of Chongqing Municipality (cstc2020jxjl-jbky10003).

\section{References}

[1] Z. Zhao, Z. Liang, K. Chan et al., "A unique issue in the standardization of Chinese materia medica: processing," Planta Medica, vol. 76, no. 17, pp. 1975-1986, 2010.
[2] S. Wang, X. Wu, M. Tan et al., "Fighting fire with fire: poisonous Chinese herbal medicine for cancer therapy," Journal of Ethnopharmacology, vol. 140, no. 1, pp. 33-45, 2012.

[3] H. Sheridan, B. Kopp, L. Krenn, D. Guo, and J. Sendker, "Traditional Chinese herbal medicine preparation: invoking the butterfly effect," Science, vol. 350, no. 6262, pp. S64-S6, 2015.

[4] J. Wang, L. Wang, G.-H. Lou et al., "Coptidis Rhizoma: a comprehensive review of its traditional uses, botany, phytochemistry, pharmacology and toxicology," Pharmaceutical Biology, vol. 57, no. 1, pp. 193-225, 2019.

[5] B.-L. Ma and Y.-M. Ma, "Pharmacokinetic properties, potential herb-drug interactions and acute toxicity of oral Rhizoma coptidisalkaloids," Expert Opinion on Drug Metabolism and Toxicology, vol. 9, no. 1, pp. 51-61, 2013.

[6] Z. Wang, Y. Yang, M. Liu et al., "Rhizoma Coptidis for alzheimer's disease and vascular dementia: a literature review," Current Vascular Pharmacology, vol. 18, no. 4, pp. 358-368, 2020.

[7] D. Zhu, Danxi's Mastery of Medicine, China Medical Science Press, Beijing, China, 2012.

[8] K. D. Park, J. H. Lee, S. H. Kim, T. H. Kang, J. S. Moon, and S. U. Kim, "Synthesis of 13-(substituted benzyl) berberine and berberrubine derivatives as antifungal agents," Bioorganic \& Medicinal Chemistry Letters, vol. 16, no. 15, pp. 3913-3916, 2006.

[9] F. Liu, Z. Zhang, J. Lai, and B. Hu, "Determination of four kinds of alkaloids from rhizoma coptis and processed rhizoma coptis by HPLC," Chinese Traditional Patent Medicine, vol. 32, no. 11, pp. 86-89, 2010.

[10] G. Wang, Bo Ji Fang, Zhonghua Book Company, Beijing, China, 1991.

[11] M. Chang, Notes on Rihuazi Medica, China Medical Science Press, Beijing, China, 2015.

[12] Chinese Medical Science Press, Pharmacopoeia of the People's Republic of China, p. 284, Chinese Medical Science Press, Beijing, China, 2020.

[13] T. T. Sham, A. C. Yuen, Y. F. Ng, C. O. Chan, D. K. Mok, and S. W. Chan, "A review of the phytochemistry and pharmacological activities of raphani semen," Evidence-Based Complementary and Alternative Medicine: ECAM, vol. 2013, Article ID 636194, 16 pages, 2013.

[14] M. N. Ghayur and A. H. Gilani, "Radish seed extract mediates its cardiovascular inhibitory effects via muscarinic receptor activation," Fundamental \& Clinical Pharmacology, vol. 20, no. 1, pp. 57-63, 2006.

[15] Y. L. Li, Y. H. Jiang, C. H. Yang, J. C. Sun, M. M. Wang, and W. Q. Yang, "Enhanced protective effect of the combination of uncaria and semen raphani on vascular endothelium in spontaneously hypertensive rats," Evidence-Based Complementary and Alternative Medicine: ECAM, vol. 2015, Article ID 358352, 11 pages, 2015.

[16] Q. Gong, Science of Processing Chinese Materia Medica, China Traditional Chinese Medicine Publishing House, Beijing, China, 2016.

[17] W. Lv, T. Ren, Y. Su, and X. Meng, "Inhibition of glucoraphenin enzymolysis in Raphani Semen by processing," Zhongguo Zhongyao Zazhi, vol. 36, no. 8, pp. 980-983, 2011.

[18] A. S. Sonmezdag, H. Kelebek, and S. Selli, "Characterization of aroma-active and phenolic profiles of wild thyme (Thymus serpyllum) by GC-MS-Olfactometry and LC-ESI-MS/MS," Journal of Food Science and Technology, vol. 53, no. 4, pp. 1957-1965, 2016.

[19] S. Gao, J. Wang, W. Qin, Y. Wang, L. Cheng, and Y. Yang, "Study on characteristic fingerprint of raw and processed 
raphani semen and changes of four chemical components," Chinese Journal of Information on Traditional Chinese Medicine, vol. 28, no. 5, pp. 70-75, 2021.

[20] W. Lv, T. Ren, Y. Su, and X. Meng, "Inhibition of glucoraphenin enzymolysis in Raphani Semen by processing," China Journal of Chinese Materia Medica, vol. 36, no. 8, pp. 980-983, 2011.

[21] L. Zhu, S. Yu, X. Zhang, H. Zhou, and H. Sheng, “Analysis on changes of chemical components in enzymolysis process of raphani semen pieces based on HPLC-DAD characteristic spectra," Chinese Journal of Experimental Traditional Medical Formulae, vol. 25, no. 4, pp. 140-145, 2019.

[22] M. S. Malik, M. B. Riley, J. K. Norsworthy, and W. BridgesJr, "Glucosinolate profile variation of growth stages of wild radish (Raphanus raphanistrum)," Journal of Agricultural and Food Chemistry, vol. 58, no. 6, pp. 3309-3315, 2010.

[23] O. A. Okunade, S. K. Ghawi, L. Methven, and K. Niranjan, "Thermal and pressure stability of myrosinase enzymes from black mustard (Brassica nigra L. W.D.J. Koch. var. nigra), brown mustard (Brassica juncea L. Czern. var. juncea) and yellow mustard (Sinapsis alba L. subsp. maire) seeds," Food Chemistry, vol. 187, pp. 485-490, 2015.

[24] R. Iori, J. Barillari, E. Gallienne, C. Bilardo, A. Tatibouët, and P. Rollin, "Thio-functionalised glucosinolates: unexpected transformation of desulfoglucoraphenin," Tetrahedron Letters, vol. 49, no. 2, pp. 292-295, 2008. 